\title{
Recreación, juego y decolonialidad: una aproximación urgente y necesaria*
}

\author{
Néstor Daniel Sánchez Londoño*
}

Recibido: 8 de octubre de 2019 • Aceptado: 27 de enero de 2020

\section{Resumen}

Este es un ejercicio de reflexión que conjuga elementos de revisiones teóricas elaboradas en algunas prácticas de investigación en las que se ha tenido la oportunidad de participar. El documento presenta definiciones sobre conceptos que se emplean como sinónimos e intenta demarcar una línea necesaria entre estos. Posteriormente, trata de dar una mirada crítica sobre el juego, desplazado por los españoles, que fue proscrito para imponer nuevas formas de jugar enfocadas más a los intereses de la cosmogonía que se implantaba. Se identifica también cómo las formas jugadas que nos impone el mundo globalizado también desplazan y menosprecian acciones de juego que se reconocen como tradicionales y cómo las nuevas propuestas resquebrajan aspectos que en el juego se favorecían tales como el desarrollo de la autonomía, la construcción social de los acuerdos y la inserción en la cultura y la sociedad a partir de un anclaje en el territorio como lugar real y simbólico para construir referentes de libertad. Finalmente, el documento propone una mirada crítica al juego, a la recreación y a las formas de entretenimiento que

Artículo de reflexión, Centro Internacional de Educación y Desarrollo Humano (Cinde), Universidad Minuto de Dios.

Citar como: Sánchez, N. (2020). Recreación, juego y decolonialidad: una aproximación urgente y necesaria. Revista de Investigación Cuerpo, Cultura y Movimiento, 10(1), 133-153 DOI: https://doi.org/10.15332/2422474x/5965

** Magíster en educación y desarrollo humano. Cinde - Universidad de Manizales. Miembro del grupo de investigación de Desarrollo rural y educaciones rurales. Correo electrónico: ndanielocio@gmail.com; nsanchez@cinde.org.co oRCID: https://orcid.org/0000-0002-9536-7424 
se imponen, y concluye que la diversión en la cotidianidad puede favorecer un proceso recreativo que nos construya como pueblo.

Palabras clave: lúdica, entretenimiento, tiempo libre, desarrollo humano, ocio. 


\title{
Recreation, game and decoloniality: an urgent and necessary approach
}

\begin{abstract}
The article presented below is a reflection exercise that combines elements of theoretical revisions elaborated in some research exercises in which we have had the opportunity to participate. The document presents definitions of concepts that are used as synonyms and attempts to delineate a necessary line between them; later it tries to give a critical view about the game, displaced by the Spaniards, that was banned in order to impose new ways of playing that served more to the interests of the cosmogony that was imposed; the document also attempts to identify how the forms played imposed on us by the globalized world also displace and belittle game actions that are recognized as traditional and how the new proposals break down aspects that were favored in the game such as the development of autonomy, social construction of agreements and integration into culture and society from a fastening in the territory as a real and symbolic place to build referents of freedom. Finally, the document proposes a critical look at the game, recreation and forms of entertainment that are imposed, proposing that fun in everyday life can favor a recreational process that builds us as a people.
\end{abstract}

Keywords: ludic, entertainment, free time, human development, leisure. 


\section{Introducción}

En este artículo de reflexión trabajaremos un primer acercamiento a los antecedentes del juego en América Latina y las formas como este fenómeno ha sido desplazado en todos los órdenes: práctico, académico y existencial, en tanto los juegos autóctonos y diversas expresiones recreativas han sido reemplazadas por lo que la modernidad/colonialidad nos ha impuesto (léase juegos tradicionales), como el desplazamiento de estos a un lugar cronológico también subalternizado por la ciencia moderna. Finalmente, se abordarán nuevas formas de entretenimiento que desplazan las formas autóctonas y tradicionales con las que los habitantes de esta parte del mundo nos encontrábamos.

Se trata de una mirada crítica que no pretende anclarnos a las cavernas desconociendo las posibilidades que nos traen los nuevos tiempos, pero sí de una apuesta por reconocer algunos elementos que subyacen tanto a las formas de entretenimiento como a las posibilidades y limitaciones que de cada una de ellas emanan. Apostamos por una mirada crítica del juego y su campo de estudio, la recreación y sus aportes al desarrollo de las personas, y buscamos develar algunas nuevas formas de entretenimiento que reviven aquellas expresiones cortesanas que, en lugar de favorecer los encuentros y las construcciones colectivas, apuestan por la individualidad en lugar de la comunitariedad, por la pasividad en lugar del movimiento, por el silencio en lugar de la conversación y nos alejan del conflicto como lugar de constitución de la subjetividad y de la sociabilidad (Bergua, 1996).

Finalmente, abordaremos el juego en el quehacer recreativo y su importancia en el desarrollo humano y social, articulando esta mirada con revisiones propias de lo que podemos denominar las nuevas formas de entretenimiento.

\section{Antecedentes del juego y el jugar en diversos campos}

Para conocer una determinada sociedad en una época concreta es importante conocer sus fiestas, juegos y diversiones

(López C., 1992, p. 311)

En esta reflexión, juego y juguetes no son palabras sinónimas. Comprendemos el juego como una acción propia del ser humano, sin querer decir que los 
animales no juegan, sino que nos centramos en una condición particular y es la del ser humano, y el juguete es un artefacto que se utiliza en el juego (Newson y Newson, 1999). De la misma manera, el juego y el jugar son dos palabras que denotan dos asuntos diferentes: por un lado, el juego se refiere a una categoría que se ha construido a lo largo de diversas reflexiones teóricas ancladas a diferentes corrientes; por otro lado, jugar se refiere exclusivamente a una acción humana que denota movimiento. No es nuestra intención calificar la intensidad de este.

El juego ha sido un fenómeno abordado desde diversas disciplinas y corrientes de pensamiento. Hasta hace algunos años, en el ámbito académico se erigieron algunas expresiones que catalogaban el jugar como un asunto propio de los humanos, basados en teorías especulativas que denotaban juicios más que resultados de procesos investigativos. Entre algunas expresiones de estas recordamos:

- Los niños y las niñas juegan para quemar energías sobrantes.

- Los juegos de los niños se dan como una preparación para ser adultos.

Estas expresiones superadas ya, a nuestro juicio, comportan dos aspectos censurables en este horizonte reflexivo. Por un lado, el juego se ha ubicado en la infancia (Mantilla, 1991) como lugar cronológico de la existencia, pero se ha olvidado que este no es un fenómeno exclusivamente infantil. Por otro lado, se desconocen de plano dos aspectos que subyacen a la práctica de cualquier juego o actividad recreativa, primero, la capacidad del sujeto a decidir sobre lo que desea hacer y, segundo, se concibe la infancia como un lugar de moratoria de la adultez que no logra tener los elementos propios que conllevan ejercicios de autonomía; asimismo, se niega la posibilidad del sujeto infantil de ser, en tanto es catalogado como un adulto en potencia. El mundo se ve y se mide desde la adultez.

Esta mirada desconoce el interés primigenio de los seres humanos por la diversión (Antoñanzas, 2005). Es importante tener en cuenta que la recreación y el juego son categorías más contemporáneas que la diversión misma. El juego es un poco más antiguo como fenómeno y como categoría (Paredes, 2002) que la recreación; esta última emerge como respuesta al tiempo libre dada la conquista de lo que Dumazedier llamó las tres D: descanso, diversión y desarrollo (Miranda, 2006). En El derecho a la pereza Paul Lafargue (1980) 
nos deja claro por qué fue necesario que los obreros lucharan por sus derechos y con ello reivindicaran el derecho al ocio y al tiempo libre; este último es más una categoría socioeconómica (Zamora y García, 1988).

Han transcurrido muchos años para que lográsemos concretar la categoría "recreación" como el lugar de la vivencia de diversas manifestaciones de carácter autotélico, que son aquellas con su fin en sí mismas. Al respecto, la diferencia que hace Byung-Chul Han entre las actividades que tienen un fin fuera de sí, como lo es el trabajo y las actividades que tienen un fin en sí mismas (2018) como el juego, la lectura, el turismo, entre otras.

\section{El juego'}

El juego y diversas formas de entretenimiento son prácticas con las que todos los seres humanos nos encontramos familiarizados de alguna manera (Fink, 1966; Gerlero, 2018). Estos fenómenos están ligados a la vida humana de formas particulares; todos y todas hemos tenido acercamiento a estas desde experiencias íntimas que están impregnadas en la piel y que se situaron allí en un momento cronológico de nuestra vida, particularmente con el juego como lo plantea Holzapfel (2011).

A diferencia del juego, que es una práctica generalmente anclada a la vida infantil, y de las acciones recreativas, entendidas como "el conjunto de actividades a través de las cuales se puede experimentar y disfrutar el ocio" (Gerlero, 2018, p. 21), las otras manifestaciones recreativas y de entretenimiento se conciben vinculadas estrechamente a la vida de los jóvenes y los adultos. Sin embargo, es menester tener en cuenta que el entretenimiento, el ocio y otras manifestaciones recreativas de disfrute de las poblaciones están identificados en otros momentos históricos fundamentalmente por razones de los análisis socioeconómicos (Han, 2018).

1 Este apartado está tomado de la ponencia: Recreación, juego, ocio, tiempo libre y entretenimiento una mirada desde el desarrollo humano en clave de ruralidad: retos y desafíos para la implementación del nuevo plan nacional de recreación en territorios rurales; presentada en Expo Recreación 2019 por el autor. También tiene como base las tesis de maestría: Expresiones alternativas desde el juego la diversión y la fiesta como acciones de transformaciones sociales con jóvenes en la ciudad de Medellín y la tesis: Juego y Bienestar laboral; en ambas, el autor de este artículo ha sido coautor. 
Siguiendo en esta línea de reflexión, el historiador holandés Johan Huizinga en su libro Homo Ludens (1971) logra develar la relación profunda que existe entre juego y cultura. Si bien algunas afirmaciones del autor hoy las consideramos superadas, muchas discusiones y letras han emergido a partir de su trabajo y ello lo sigue haciendo un texto de obligada consulta. Sus aportes nos han permitido acercarnos a autores como Eugen Fink, que consideran al juego como una condición vital de la existencia (1966).

Algunas perspectivas más de corte psicológico, horizonte donde más se ha abordado este tópico, han ubicado el juego en el momento cronológico de la infancia como un lugar casi exclusivo (Mantilla, 1991), que desconoce de tajo el espíritu lúdico inmerso en la condición humana. En este sentido, de acuerdo con Mantilla, se configura un binomio indisoluble entre niño y juego que niega, seguramente sin pretenderlo, las posibilidades juguetonas de otros protagonistas menos infantiles y más curtidos por el peso de los años, pero no menos humanos.

Ancladas en la industria de la diversión, algunas expresiones siguen siendo usadas en prácticas recreativas que por algunos intereses ubican el juego en el lugar de la infancia cada vez que se arguye la necesidad de "sacar el niño que se tiene al interior" para que los adultos puedan participar activamente de estos eventos. Esta postura olvida que el juego está profundamente ligado a la cultura de acuerdo con lo que nos plantea Huizinga y que ser joven o adulto no ha significado, en ninguna circunstancia, estar al margen de esta y que la misma dimensión lúdica (González, 2010) se encuentra ligada a la existencia desde su nacimiento hasta que esta expira en la condición individual del sujeto.

Los vocablos jugar, juego, juguete, lúdica, entretenimiento, tiempo libre, ocio y recreación son utilizados vulgarmente para referirse al juego o a la acción misma de jugar y pocas veces nos detenemos a pensar en las implicaciones de cada una de estas palabras y sus acepciones, y las consecuencias de estas tanto en nuestras prácticas como en las reflexiones que se precian de recogerlo teóricamente. En este documento abordaremos unas pocas que consideramos la base de la recreación, el ocio y el entretenimiento, pues parecen ser los únicos conceptos que soportan estas categorías. Al respecto, esa aparente confusión conceptual no es más que otra muestra de la manera marginal y despreocupada con la que se lee el fenómeno, y desconoce en muchas ocasiones algunos aspectos básicos de las construcciones que han realizado otros y otras que nos anteceden. 
El jugar se entiende como una práctica humana (Ambrosini, 2007), lejos de las nubes de colores que lo aíslan y lo conectan con lo irreal; esta es una acción concretamente humana que se da en la interacción propia de la cotidianidad. En el caso del jugar humano, usaremos la expresión de Eugen Fink (1966, p. 7): "Jugar no sucede sin más en nuestra vida, es un suceder aclarado significativamente". En este sentido, consideramos el jugar como una práctica que se vive conscientemente y no como una preparación para el ejercicio de vidas posteriores, en el caso de la infancia, o como escapes sociales que regulan maneras de comportarse adquiriendo aprendizajes que se hacen necesarios para el futuro. El jugar se refiere a la realización de prácticas de juego que varían de acuerdo con la cultura y el mundo social en el que nos encontramos inmersos. Una acción jugada en una latitud o en otra puede tener diferentes expresiones, tanto en sus acciones como en sus locuciones; incluso los significados pueden variar de acuerdo con los valores o creencias que logran construirse en el entramado social y cultural que les acoge (Piaget, 1979).

De acuerdo con Mantilla (1991), el que juega ejercita lo que sabe. Esta afirmación creemos que nos ayuda a superar algunas posturas que ubican el juego única y exclusivamente como un ejercicio de aprendizaje o como preparaciones para el ejercicio de la condición adulta. El jugar no es una práctica sin sentido en la vida humana; este se da en las posibilidades de interrelaciones que construimos y ayuda de manera clara a crear los símbolos que nos permiten reconocernos en el conglomerado al que pertenecemos. El juego, en este caso, es una acción que se caracteriza por la "autonomía del movimiento" (Gadamer, 1991, p. 11) y se ejerce en el presente con conciencia de su realización.

Los juguetes no son más que artefactos "utilizados para llevar a cabo posibilidades de la diversión” (Antoñanzas, 2005, p. 11), anclados a este interés humano del placer impregnado en nuestra existencia desde el principio de la historia de la humanidad. Podríamos decir que "a todo juego le corresponde la utilización de un juguete" (Newson y Newson, 1999, p. 34), que es, sin duda, una propuesta creativa que termina acompañando la acción de jugar de manera decidida por el sujeto que juega. A la manera de Newson y Newson (1999) estos son inverosímiles, pero dependen de la creatividad del jugador.

En palabras de Julia Gerlero (2018, p. 21), la recreación se comprende como "el conjunto de actividades a través de las cuales se puede experimentar y disfrutar el ocio". Ello concuerda con la tesis de Osorio (2019), quien logra definir la recreación como el lugar de disfrute del ocio, vinculado por 
los espacios-tiempo de las personas de acuerdo con el lugar social y cultural en el que se encuentren vinculados.

Finalmente, la lúdica hoy la comprendemos como una dimensión humana (González, 2010) que, digamos de alguna manera, recoge el juego pero que no se agota en el mismo, pues son múltiples las maneras y formas como los seres humanos apuestan por la diversión, el entretenimiento, el goce y el disfrute, limitados, claro está, por las regulaciones que la cultura construye para evitar caer en desmanes e infortunios. Parafraseando a Carlos Bolívar (1998), la lúdica es la dimensión humana que se refiere a la capacidad de goce del ser humano, que nace con él y que desaparece con su existencia. La lúdica no es un elixir extraído de los más recónditos lugares después de condensar el extracto de las más finas hierbas; su presencia está ligada a la existencia humana cuando esta emerge en el milagro de la vida (Molina y Sánchez-Londoño, 2017). De esta manera, las condiciones sociales que acompañan nuestra existencia, nuestras relaciones y los espacios geográficos que circundan nuestras acciones, entre otros, determinan las formas como se expresa nuestra dimensión lúdica y sus escenarios se nos convierten en un suceso que expande nuestro ser y favorece posibilidades para el desarrollo.

En palabras de Vera Barros (2010, p. 102), “el juego nos lanza en la dirección del otro", y este asunto se reconoce en Fink cuando nos plantea que todo juego tiene un horizonte comunitario (Fink, 1966). La dirección del otro es la posibilidad de su encuentro que construye y propone alternativas para esculpirnos y construir nuestra subjetividad y la de nuestro congénere. Ese encuentro con el otro se torna comunitario cuando es posible que nos construyamos mutuamente. Podríamos decir a la sombra de Barros (2010) y Fink (1966) que la recreación, el ocio y diversas formas de entretenimiento están ligados extraordinariamente a la vida humana y que su conexión es profundamente cultural sin olvidar su condición biológica y existencial. En otras palabras, recreación, juego, jugar, juguete y lúdica no se comprenden como sinónimos, sino como palabras con acepciones diferentes cada una, que no pueden tratarse ligeramente en abordajes teóricos que se precien de mínimos necesarios para la discusión.

Siguiendo a Gadamer (1991, p. 31): "El juego es una función elemental de la vida y que no es posible pensar en la cultura humana sin un componente lúdico". No es otra cosa que afirmar que no es posible vivir sin la diversión, sin el disfrute, el goce y el entretenimiento que puedan generar en cada cultura 
o latitud las propuestas que allí se construyen. Entonces, la dimensión lúdica, como aspecto sustancial de la existencia, está ligada a aquella de manera intrínseca y que cada persona en su configuración subjetiva deja expresar su capacidad de goce y placer, anclado, de manera profunda, al devenir que lo ha construido. Por ejemplo, en la historia de los juguetes se han encontrado suficientes indicios para afirmar que es la historia de la humanidad por cuanto estos artefactos se construyen con los materiales y valores que cada época reconoce como tal (Antoñanzas, 2005).

El juego y la recreación han estado inscritos en la vida infantil y pocas miradas apuntan a reconocerles como prácticas existenciales fundamentales, más arraigadas a la vida humana que a una etapa cronológica de ella. El juego en particular tiende a ubicarse, como es usual, en una actividad marginal que se utiliza como escape de la vida cotidiana y no como una posibilidad de construcción y desarrollo de las personas que les permiten, por el contrario, enfrentar la vida y transformarla (Osorio, 2019). Se olvida con facilidad que estos fenómenos hacen parte de nuestra vida y que su práctica, lejos de ser actividades banales, favorecen nuestro desarrollo en la medida que posibilitan nuestros encuentros y la construcción de relaciones que nos constituyen como sujetos.

El juego ha sido abordado desde múltiples disciplinas y corrientes: la psicología, (Mantilla, 1991; Piaget, 1979); la sociología (Caillois, 1997), la antropología (Duvignaud, 1997) y la filosofía (Holzapfel, 2011; Gadamer, 1991), la historia y la filosofía (Huizinga, 1971), solo por mencionar algunos autores.

En la actualidad, al menos en América Latina, desde el campo recreativo se han abordado conceptos muy importantes como el juego, el ocio y el entretenimiento con una mirada más anclada al desarrollo de los seres humanos; al respecto pueden revisarse autores como Byung-Chul Han (2018), Esperanza Osorio (2019) y Julia Gerlero (2018). En otros escenarios se ha considerado el estudio del fenómeno del jugar anclado al desarrollo humano, pero lejos de procesos sociales, culturales, económicos y políticos y, claro está, al margen de la recreación como su campo aglutinador junto a otras expresiones propias del entretenimiento de los seres humanos (Sánchez et al., 2014). Es respetable una postura que decida desvincular el juego de la recreación; sin embargo, esta puede caer en el peligro de totalizar una práctica desde miradas particulares y limitadas o desde las características que este fenómeno conlleva; una de estas es el juego como fin en sí mismo, que no es otra cosa que su carácter autotélico. Definir el juego solamente desde esta característica se traduce en 
una mirada parcializada de un fenómeno más amplio; además, es necesario tener en cuenta que es una característica de todas las prácticas recreativas en los tiempos-espacios de ocio y recreación.

A nuestro juicio, huirle a la reflexión del campo de la recreación y aislar el juego de esta es una forma de totalizar el fenómeno y falsear sus lecturas y los posibles resultados que puedan desprenderse de procesos abordados con el fenómeno mencionado. Al respecto de este desarrollo, se han conocido diversos procesos de investigación que contemplan el juego anclado a la vida de los seres humanos y a sus procesos de desarrollo, como Jesús Paredes en $E l$ deporte como juego, un análisis cultural (2002) en el que dedica un capítulo al juego y su presencia en las diversas culturas, y Fernando Antoñanzas, con la investigación doctoral Artistas y juguetes (2005), en la que da cuenta de la importancia de los juguetes y los juegos en los pueblos y así muchos otros autores que hablan del juego y el desarrollo humano y comunitario (Molina y Sánchez-Londoño, 2017).

\section{El juego y el jugar en el concierto latinoamericano ${ }^{2}$}

En América Latina, las formas de jugar están necesariamente marcadas por la modernidad/colonialidad; la invasión española marcó un hito muy importante en este fenómeno y en las formas como este se desplegó en los siguientes años hasta nuestros días (Jiménez, 2007; Araya Espinosa, 1999).

Los juegos son una expresión de la cultura y responden a las formas culturales y de sociabilidad construidas por los diferentes grupos humanos (Paredes, 2002). Nos atrevemos a decir que no es posible que una sociedad construya juegos y expresiones recreativas por fuera de sus marcos simbólicos o de referentes de otros órdenes; los juegos son representaciones microscópicas de las relaciones y de la vida en sociedad. Como dijera López (1992), si estamos interesados en conocer una determinada sociedad, basta con conocer sus fiestas, sus juegos y sus diversiones. La cosmovisión de un determinado grupo social define los juegos de una sociedad y las diferentes expresiones recreativas.

2 Este apartado está tomado y adaptado de la ponencia Recreación, juego, ocio, tiempo libre y entretenimiento una mirada desde el desarrollo humano en clave de ruralidad: retos y desafíos para la implementación del nuevo plan nacional de recreación en territorios rurales; presentada en Expo - Recreación 2019 por el autor. 
Las formas de juego autóctonas, practicadas por los indígenas que habitaban estas tierras antes de la invasión española y de las que se cuenta con pocos registros, fueron desplazadas por los foráneos de múltiples maneras; al respecto puede verse la investigación de Orián Jiménez (2007) que da cuenta de las formas diversas de desplazamientos de las costumbres indígenas para que pudiesen disciplinarse cultural y corporalmente a las nuevas relaciones de producción impuesta por los invasores.

Es de anotar que todas las culturas han jugado y desarrollado diferentes expresiones propias para su entretenimiento (Verdú et al., 2003); en el caso de los indígenas, las expresiones festivas fueron prohibidas por el poder colonial en tanto se convertían en espacios de encuentro y conatos de rebelión (Castro, Hidalgo y Briones, 2002).

Para los españoles, las formas de relacionamiento que los indígenas tenían con el trabajo eran bastante sospechosas y por ello debía ser reemplazada por una relación más "civilizada"; ello implicaba una sujeción a jornadas laborales que estaban determinadas por el tiempo de acuerdo con la modernidad/colonialidad (Tabares, 2011). Para la población autóctona, esta paralización era incomprensible y no necesariamente por un asunto de atraso cognitivo, sino porque el mundo fundaba con la invasión, la colonialidad en la que la idea de verdad y de conocimiento ya era eurocéntrica (Mignolo, 2007). Lo anterior hizo que los invasores propusieran nuevas formas de juego y de expresiones recreativas que ayudaran a que los nativos se disciplinaran cultural y corporalmente, como ya se ha manifestado, y pudiesen sujetarse a las formas de relacionamiento laboral y de otros órdenes que se imponían (Jiménez, 2007; Tabares, 2011). Aparecen en la escena colonial y moderna juguetes de mesa para que se lograra el objetivo del disciplinamiento y fuese posible que los aborígenes se vincularan a las nuevas faenas sin mayores dificultades.

La modernidad/colonialidad desplaza las formas autóctonas de relacionamiento y con ellas los juegos y expresiones de entretenimiento más cercanas al rito, a la fiesta (Segalen, 2014) y a las formas como las poblaciones y los diferentes grupos humanos construyen eso que Óscar Vahos (2000) denominó los sistemas lúdicos.

El siguiente apartado abordará una mirada al juego en clave de la modernidad/colonialidad y su papel con relación a los mismos procesos de dominación a los que seguimos asistiendo. 


\section{Una mirada a las nuevas formas de entretenimiento ${ }^{3}$}

Las formas de entretenimiento a las que asistimos actualmente están íntimamente ancladas al mundo neoliberal y a su sistema económico, político y social o a lo que nos queda a partir de la implantación de este en el continente y concretamente en Latinoamérica. El neoliberalismo no es exclusivamente una propuesta económica sino una agenda social y cultural que pretende colonizar todas las formas de relaciones (Yeldan, 2007) que pudiésemos imaginar o construir.

Nuestras formas recreativas o, como dijera Óscar Vahos (2000), nuestros sistemas lúdicos han estado al vaivén de las formas de colonización que hemos vivido (Mignolo, 2007). De ello no se alejan ni los juegos ni las diversas formas de recreación, diversión o entretenimiento que se han construido a lo largo de la historia, y con ello nos referimos a juegos, fiestas y diversiones propias de esta tierra, bastante diezmadas por los españoles cuando necesitaron disciplinar cultural y corporalmente a los indígenas (Jiménez, 2007) y a los esclavos traídos de África.

El campo recreativo es considerado como un estudio marginal que poco o nada tiene que ver con el desarrollo de las personas (Tabares, Ossa y Molina, 2005; Osorio, 2019). Las ofertas recreativas y de juego que se hacen en los municipios, los departamentos y en muchos rincones del país desconocen la existencia de una política pública en la materia y, por ende, no se tiene en cuenta el plan nacional de recreación (Coldeportes, 2013) a la hora de ofertar propuestas de juego que deberían impactar en la vida de las personas. A esta marginalidad política se suma la marginalidad académica, el juego, la recreación, el ocio y el tiempo libre, asumidos peyorativamente pues no "sirven para nada"; están al margen de la academia, aunque existen bastantes reflexiones e investigaciones que pueden ayudarnos a comprender la importancia de estos tópicos en la vida de los seres humanos. Este aspecto ya lo hemos mencionado anteriormente. En palabras de Duvignaud, “el positivismo ha logrado eliminar lo que estorbaba a su visión plana del universo" (1997, p. 5).

Esta marginalidad también tiene que ver con el menosprecio por un saber que ha buscado comprender aspectos de la vida que no están ligados

3 Este apartado hace parte de la ponencia presentada por el autor en Expo Recreación 2019; se encuentra ampliada y ajustada en clave del propósito de la invitación que se nos hace. 
a lo productivo en tanto su sentido se encuentra en sí mismo (Han, 2018), pero también con las formas coloniales que subalternizan un conocimiento propio de otros lugares y otros escenarios (De Sousa, 2001; Tabares, 2011). La recreación, la fiesta, la diversión, el entretenimiento, el juego, si logran ser coptados por el mercado, ingresan a los análisis macroeconómicos (Pujol, 2013) y a la misma academia; términos como la gamificación (Sigala, 2015) y otros vienen cobrando fuerza en el mundo empresarial para aumentar los niveles de productividad y ahora se trasladan a la escuela con pocas reflexiones sobre su sentido teleológico, que obligan a abordar "el juego con sentido" que se reclama tanto por "ciertos pedagogos" como por empresarios que ven en el juego una posibilidad de mayor producción olvidando al ser humano que produce.

El reclamo por un juego con sentido obedece al interés de ludificar la existencia en su totalidad (Han, 2018) para que las personas se autoexploten en su tiempo libre. La globalización ya logró comprender que un sujeto que se expande desde la diversión puede ser más productivo y logra sumergirse en sus intereses sin mucho recato; en palabras de Byung-Chul Han: "El poder que entretiene es más poderoso que el poder que trabaja con la coerción” (2018, p. 40); entra en escena entonces el management emocional (Han, 2014).

Es necesario mencionar que, así como en la invasión y posteriormente en la Colonia los juegos autóctonos que existían y que eran parte de la cosmovisión indígena fueron desplazados por las formas de diversión traídas por los recién llegados (Jiménez, 2007), en la actualidad los juegos construidos a partir del mestizaje y la interculturalidad y que ahora consideramos como nuestros, y que denominamos tradicionales, los están desplazando los juguetes que impone la modernización globalizadora. Dicha dinámica impone nuevas formas de jugar y de relacionarse que requieren de un análisis más exhaustivo y riguroso para desentrañar las formas de socialización que de ellas emanan, los horizontes a los que nos quieren acercar y si su interés está centrado en lo humano o en formas de alienación que resquebrajan el tejido social que se construye desde el juego, la diversión, el entretenimiento, desde la recreación y el ocio, dado que nuestros juegos y formas de diversión fueron vetadas, pues en estos se identificaron formas de resistencia y conatos de rebelión:

[...] que se observen con disimulo, como lo he practicado por medio de ministros de cordura, y mas los dias de regocijos y festividades que estan muy expuestos á la embriaguez y juntas, pues en las que tubieron por 
espacio de dos años en diversos y retirados sitios, alentaron su maquinación y le aumentaron sus cómplices. (Memorias, t. 4, 1856: 98 citado por Castro, Hidalgo y Briones, 2002, p. 77) ${ }^{4}$

Al respecto, en este trasegar investigativo y de prácticas recreativas en diferentes ámbitos, logramos develar que tres aspectos se resquebrajan con las nuevas formas de jugar:

- La relación juego, jugador y juguete

- Las formas de socialidad

- La construcción de arraigo, libertad y autonomía

A continuación veremos de manera breve cómo estas nuevas formas de juego y entretenimiento resquebrajan aspectos importantes en los que el juego y la recreación aportan en el desarrollo de los seres humanos.

\section{La relación juego, jugador y juguete}

Esta triada juego, jugador y juguete ha implicado una relación más estrecha de lo que parece. Para intentar entender esto, tendremos que manifestar que comprendemos el juego como el jugar mismo, en tanto acción; el juguete como un artefacto (Molina y Sánchez-Londoño, 2017) con el que se juega y el jugador como el sujeto que juega.

La relación construida en esta triada es una relación simbólica que determina el papel de cada uno de los tres protagonistas identificados; el jugador define una forma de jugar con un artefacto denominado juguete. Ya había mencionado Walter Benjamin (2017) cuán equivocados estamos cuando la supremacía la tiene el juguete y este determina la forma de jugar. En la acción de jugar, el jugador es quien determina la dinámica del juego y el juguete que ha de usarse, además del uso que se le da a este. Esta forma de relacionamiento le da primacía al jugador y este decide qué jugar, cuándo, dónde, cómo, con qué y los usos de los artefactos que se emplean; en este sentido, se da una formación en la construcción de la autonomía del jugador que se da de manera

4 No se hacen corrección de algunas expresiones que pudiésemos identificar como mal escritas, debido a que es un aparte extraído textualmente. 
diferente en otras acciones; sucede lo mismo con la capacidad imaginativa del jugador en la medida que crea mundos y determina en este las formas de relacionamiento. No es un asunto menor que esta relación favorezca estas dos dimensiones de la existencia de los seres humanos, la autonomía y la capacidad imaginativa.

Con los juguetes modernos, propios del neoliberalismo y la globalización, la primacía la tiene el juguete, que determina las formas de jugar. Valdría la pena indagar un poco más los pormenores de esta relación y qué sucede con los tópicos mencionados, cuáles serían las características de la construcción de autonomía con un juguete y una forma de jugar que determina las acciones del jugador y qué sucede con la capacidad imaginativa de quienes ya no tienen muchas opciones de crear sino de anclarse a lo dado por parte de un programador.

\section{Las formas de sociabilidad}

Las formas de sociabilidad, comprendidas como aquellas posibilidades de encuentro, de construcción de acuerdos y de sentidos para afrontar la existencia de cada uno (Bergua, 1996) se dan en el jugar de una manera natural; los acuerdos para que el juego sea posible están a la orden del día, no es posible jugar sin acuerdos (Molina y Sánchez-Londoño, 2017). La no construcción de acuerdos hace imposible el jugar cualquiera que sea la clasificación que se haga de estos; en los sistemas lúdicos de los que nos habla Óscar Vahos (2000), el juego está anclado a formas rituales de relacionamiento con todo, con los otros, con lo otro y con las formas como los seres humanos construyen sus relaciones para darles un cierto orden (Segalen, 2014); este no se impone por foráneos, sino que es construido en las relaciones sociales jugadas que se presentan a temprana edad y se mantienen en las diversas manifestaciones recreativas a lo largo del curso de vida.

En este sentido, el juego cumple un papel importante en el desarrollo de ciertas formas culturales y sociales, tanto para perpetuar formas de relacionamiento como para transformarlas (Molina y Sánchez- Londoño, 2017). La referencia de lo anterior está vinculada a los juegos autóctonos $\mathrm{y}$ tradicionales.

A partir de la globalización seguimos anclados al paradigma de la modernidad/colonialidad, que con nuevas tecnologías da entrada a juguetes mucho 
más sofisticados en el que las habilidades visomanuales tienen una cierta preponderancia; sin embargo, no son los únicos juguetes que se elaboran y se despliegan por doquier. En este sentido, los nuevos juguetes proponen formas diferentes de vincularse a los acuerdos que ya no es necesario construir o simplemente son los juguetes los que determinan las acciones del jugador.

En clave de la reflexión que venimos haciendo, las formas de socialización sufren un vuelco importante: por un lado, ya no son los jugadores quienes construyen acuerdos para jugar y enfrentar juntos los asuntos que se avecinan en el juego, por otro lado, son los juguetes los que determinan la manera como el jugador entra en el juego. El cambio es significativo en tanto le suprime protagonismo al jugador y lo obliga a jugar bajo sus reglas. Antaño eran los jugadores los que definían la forma y acuerdos para el juego.

Solo nos queda preguntarnos por el desarrollo de una socialidad guiada por ordenadores y programadores a una que se encuentra mediada por las relaciones que obligan al otro a definir sus intereses y concertar para que sea posible el juego y las diversas prácticas recreativas.

\section{La construcción de arraigo y libertad}

Las formas de jugar están ancladas a un territorio, a una territorialidad y a un entramado de relaciones simbólicas que construyen al sujeto que juega; cada juego es en esencia una partícula de cultura, de sociedad, de relaciones y de ritos. Este, como la recreación, no es un fenómeno aislado de las condiciones sociales económicas, culturales y políticas de los individuos y de las sociedades mismas.

Los anclajes que el juego ayuda a construir a los jugadores, con sus amigos, con el territorio, con las costumbres, con las reglas socialmente establecidas no son más que elementos que le permiten construir las bases para la libertad misma, en palabras de Han, lo que nos hace libres no son las falta de lazos y arraigo sino por el contrario la existencia de estos realmente nos hace libres; "son los vínculos y la integración" (Han, 2018, p. 53).

En este contexto, los juegos actuales carecen de referentes geográficos, para jugar estamos fuera de nuestra órbita, y ello supone un ejercicio engañoso de la libertad. Cabe preguntarnos entonces por las consecuencias de juegos que nos descentran del lugar que nos construye en términos de la subjetividad y de las relaciones que construimos para el ejercicio ciudadano. 


\section{A manera de conclusiones}

En América Latina hemos asistido a un juego colonial que nos ha descentrado del lugar de nuestro arraigo, desde la invasión española hasta la invasión globalizadora. En suma, seguimos asistiendo al desplazamiento de los juegos que nos han construido como pueblo, a la colonización de las formas de entretenimiento que han enajenado las expresiones ancestrales de encuentro, construcción colectiva y resistencia.

En la actualidad, los intereses que se despliegan en y desde el neoliberalismo y la globalización, centrados en la productividad, hacen que se reclame de manera permanente un juego con sentido y se menosprecia el juego espontáneo y autotélico que se practica en la cotidianidad de diferentes grupos poblacionales. Estas formas de jugar siguen apostando por el juego colonial que enajena y aísla, que cercena las formas de encuentro construidas por siglos y que disciplina a los seres humanos para la producción, y conducen al olvido del encuentro como lugar de desarrollo.

No se trata de menospreciar las formas de sociabilidad que emergen en las nuevas formas de entretenimiento, pero sí de preguntarnos por sus posibilidades y limitaciones para que no se apliquen sin preguntarnos por los horizontes que se nos quieren imponer y el lugar que ocupamos en este nuevo entramado de relaciones que nos imponen. Se trata de ayudar a construir una mirada crítica del juego en América Latina que se sume a un proyecto ético político de resistencia y de construcción en la línea del buen vivir.

\section{Referencias}

Antoñanzas, F. (2005). Artistas y juguetes [tesis doctoral]. Madrid: Universidad Complutense de Madrid.

Araya, A. (1999). Ociosos, vagabundos y malentretenidos en el Chile colonial. Santiago de Chile: LOM Ediciones.

Barros, V. (2010). Brincar com o outro. Petropolis: Vozes.

Benjamin, W. (2017). Reflexiones sobre niños, juguetes, libros infantiles, jóvenes y educación (J. J. Thomas, trad.). Oaxaca: Casa de las Preguntas.

Bergua, J. A. (1996). La socialidad lúdica juvenil. Sobre como los jóvenes erosionan el orden social cuando se divierten. Madrid. DOI: https://doi. org/10.2307/40184205 
Bolívar, C. (1998). Aproximación a los conceptos de lúdica y ludopatía. V Congreso Nacional de Recreación. Conferencia llevada a cabo en Congreso Colombiano de Educación Física y el Congreso Nacional de Recreación, Manizales, Caldas, Colombia.

Caillois, R. (1997). Los juegos y los hombres: la máscara y el vértigo. Ciudad de México: Fondo de Cultura Económica.

Castro, N., Hidalgo, J. y Briones, V. (2002). Fiestas Borracheras y Rebeliones. Revista Estudios Atacameños, (23), 77-109. Recuperado de https://revistas. ucn.cl/index.php/estudios-atacamenos/article/view/222/210

Coldeportes (2013). Plan Nacional de recreación 2013-2019. Bogotá: Ministerio del Deporte.

De Sousa, B. (2001). Epistemologías del sur. Maracaibo: Utopía y Praxis Latinoamericana.

Duvignaud, J. (1997). El juego del juego. Ciudad de México: Fondo de Cultura Económica.

Fink, E. (1966). Oasis de la felicidad. Cuaderno del centro de estudios filosóficos. Universidad Nacional Autónoma de México, (23), 31.

Gadamer, H. (1991). La Actualidad de lo Bello. Barcelona: Paidós.

Gerlero, J. (2018). Recreación y dictadura. Oaxaca: Colectivo Editorial Casa de las Preguntas.

González, D. (2010). Perspectivas del desarrollo humano. Medellín: Cinde.

Han, B. C. (2012). La sociedad del cansancio. Barcelona: Herder.

Han, B. C. (2014). Psicopolítica: neoliberalismo y nuevas técnicas de poder. Barcelona: Herder

Han, B. C. (2018). Buen entretenimiento. Bogotá: Herder.

Han, B. C. (2018). El aroma del tiempo. Barcelona: Herder.

Holzapfel, C. (2011). Fenómenos existenciales fundamentales de Eugen Fink: juego y muerte. Revista de Filosofía, (67), 201-214. Dor: http://dx.doi.org/10.4067/ S0718-43602011000100013

Huizinga, J. (1971). Homo Ludens. Barcelona: Paidós.

Jiménez, O. (2007). El frenesí del vulgo: fiestas, juego y bailes en la sociedad colonial. Medellín: Universidad de Antioquia.

Lafargue, P. (1980). El derecho a la pereza. Madrid: Fundamentos.

López, A. (1992). Juegos, fiestas y diversiones en la América española. Madrid: Mapfre. 
Mantilla, L. (1991). El juego y el jugar ¿Un camino unilineal y sin retorno? Estudios sobre las Culturas Contemporáneas, 4(12), 101-123. DoI: https://doi. org/10.35537/10915/34770

Mignolo, W. (2007). La idea de América Latina: la herida colonial y la opción decolonial. Barcelona: Gedisa. DoI: https://doi.org/10.21057/repam.v3i1.1369

Miranda, G. (2006). El tiempo libre y ocio reivindicado por los trabajadores. Pasos. Revista de Turismo y Patrimonio Cultural, 4(3), 301-326. DoI: https://doi. org/10.25145/j.pasos.2006.04.021

Molina, J. y Sánchez-Londoño, N. (2017). Expresiones alternativas de los y las jóvenes desde el juego, la diversión y la fiesta en la ciudad de Medellín como acciones de transformación social [tesis de maestría]. Universidad de Manizales, Manizales, Colombia.

Newson, J. y Newson, E. (1999). Juguetes y objetos para jugar. Nueva York: CEAC.

Osorio, E. (2019). Asuntos presentes en el campo de la recreación. Oaxaca: Casa de las preguntas.

Paredes, J. (2002). El deporte como juego: un análisis cultural [tesis doctoral]. Universidad de Alicante, Alicante, España.

Piaget, J. (1979). El juego. México: Fondo de la Cultura Económica.

Pujol, A. (2013). Ciudad, fiesta y poder en el mundo contemporáneo. Revista Estudios Sociales y Humanísticos, 4(2), 36-49. DoI: https://doi.org/10.29043/ liminar.v4i2.209

Sánchez, N., Correa, P., Salazar, I., Flórez, A., Bojacá, S., García, D., ... Pernett, L. (2014). Metodología Naves, su ser y su hacer. Bogotá: Corporación Día de la Niñez.

Segalen, M. (2014). Ritos y rituales contemporáneos. Madrid: Alianza Editorial.

Sigala, M. (2015). The application and impact of gamification funware on trip planning and experiences: the case of TripAdvisor's funware. Electronic Markets, 25. DOI: $10.1007 / \mathrm{s} 12525-014-0179-1$

Tabares, F. (2011). El conocimiento del ocio en las sociedades periféricas. Análisis de la producción de científica de ocio, recreación y tiempo libre en Colombia [tesis doctoral]. Universidad de Deusto, Bilbao, España. DoI: https://doi.org/1 $0.17227 / 01214128.20$ ludica113.118

Tabares, F., Ossa, A. y Molina, V. (2005). El ocio el tiempo libre y la recreación en América Latina. Problematizaciones y desafíos. Medellín: Corporación Cívitas.

Vahos, O. (2000). Juguemos Dos. Medellín: Realgráficas. 
Verdú, V., Rodríguez, J. L., Martínez, M., García, J. y Uría, J. (2003). Fiesta, juego y ocio en la historia. Salamanca: Universidad de Salamanca.

Yeldan, E. (2007). Globalization as the Hegemonic Concept of Neoliberal Ideology. En A. H. Köse, F. Senses y E. Yeldan (eds.), Neoliberal Globalization As New Imperialism: Case Studies on Reconstruction of the Periphery (pp. 43-54). Reino Unido: Nova Science.

Zamora, R., y García, M. (1988). Sociología del tiempo libre y Consumo de la población. La Habana: Ciencias Sociales. 